\author{
Asian Journal of \\ Medical and Biological Research \\ ISSN 2411-4472 (Print) 2412-5571 (Online) \\ www.ebupress.com/journal/ajmbr
}

\title{
Article \\ Antibacterial, antibiofilm, hemolytic activity and phytochemical study of various aerial parts of Moringa oleifera in Pakistan
}

\author{
Shahnaz Dilawar ${ }^{1}$, Afzal Shah $^{1}$, Hidayat Ullah $\operatorname{Khan}^{1}$ and Saima imad ${ }^{2}$ \\ ${ }^{1}$ Department of Chemistry, University of Science and Technology Bannu-28100, KPK, Pakistan \\ ${ }^{2}$ Chemical Meteorology Division, National Physical Standard laboratory (PCSIR), Plot No. 16, Sector H-9 \\ Islamabad, Pakistan
}

*Corresponding author: Dr Afzal Shah, Department of Chemistry, University of Science and Technology Bannu-28100, KPK, Pakistan. E-mail: afzalnm@yahoo.com

Received: 07 March 2018/Accepted: 22 March 2018/ Published: 29 March 2018

\begin{abstract}
The methanolic extracts of five aerial parts of Moringa oleifera Lam were screened for their antibacterial, antibiofilm and hemolytic activity. The phytochemical screening of the methanolic extracts of aerial parts was also evaluated. The antibacterial, antibiofilm activity of the extracts of various aerial parts of $M$. oleifera was evaluated by disc diffusion and micro titer plate assay method against two selected bacterial species. Hemolytic activity of the methanolic extracts was screened against normal human erythrocytes. Comparatively the methanolic extracts of all aerial parts were more effective against Gram positive bacteria Bacillus subtilis and Gram negative bacteria Escherichia coli (E. coli).The present study suggests that all aerial parts of this plant can be used as an antibacterial, anti-biofilm agent in treating ailments caused by the tested organisms (Bacillus subtilis and Escherichia coli). Methanolic extracts of aerial parts possessed minimum hemolytic activity. Significant antimicrobial, antibiofilm activity of the extract was found in this study.
\end{abstract}

Keywords: Moringa oleifera; methanol extracts; antibacterial; antibiofilm; hemolytic activity

\begin{abstract}
1. Introduction
The use of natural substances in the treatment of different diseases, including those of infectious disease is currently a challenge in medicine and offered an alternatives, especially in those ailments for which there is no adequate remedy (Domingo and López-Brea, 2003). Medicinal plants are significantly beneficial and economically indispensable. They are rich in a wide variety of secondary metabolites such as tannins, alkaloids flavonoids, vitamins (A, C, E and K), carotenoids, terpenoids, polyphenols, saponins, pigments, enzymes and minerals that have antimicrobial and antioxidant activity (Khan et al., 2009). Considerable attention has been paid to bio and eco friendly plants, which can prevent and cure different human diseases (Dubey et al., 2004). The antimicrobial potentiality of various medicinal plants is widely studied all over the world (Rojas et al., 2006; Arora et al., 2009). Moringa oleifera Lam is the most widely cultivated species of monogeneric family, the Moringaceae, as an important medicinal plant, which is native to, Africa, Arabia, South Asia, South America, Himalaya region, India, Pakistan, the Pacific and the Caribbean Islands (Fahey, 2005; Sreelatha et al., 2009).

Two species of Moringa, i.e., M. concanensis and M. oleifera are present in Pakistan. M. oleifera is cultured extensively all over the moderate areas of the countryside (Qaiser, 1973). In Pakistan, widely cultivated areas of M. oleifera are Punjab plains, Sindh, North western Frontier Province and the Baluchistan (Qaiser, 1973). The Moringa plant has been the object of much research due to its multiple uses and well-known bactericidal potential (Gustavo et al., 2010). Moringa oleifera is known to possess hypoglycemic, hypotensive, antimicrobial, hepatoprotective, immunomodulatory, antioxidant and antitumor activities (Mahajan et al., 2010; Sudha et al., 2010). It is one of the best known, widely distributed and grown species of a monogeneric family
\end{abstract}


moringaceae (Anwar et al., 2007). The plant is highly regarded and almost every part of the tree is used as food with high nutritional value (Chuang et al., 2007). Moringa oleifera has been reported to possess antimicrobial properties and this explains the reason for its extensive use in the treatment of human ailments (Lockettet et al., 2000). The morphological parts of Moringa oleifera against some pathogenic microorganisms have been reported (Doughari, 2007; Nikkon et al., 2003; Jamil et al., 2007: Kekuda et al., 2010). It has been revealed that the antioxidant activity of plants might be due to their phenolic compounds (Cook and Samman, 1996). Flavonoids are a group of polyphenolic compounds associated with the antioxidant activity and antiinflammatory action (Frankel, 1995). Flavonoids are known as plant pigments for over a century and belong to a vast group of phenolic compounds that are widely distributed in all foods of plant origin. North American diet, flavonoid glycosides are unavoidably consumed daily, with an estimated total consumption of $1 \mathrm{~g} / \mathrm{d}$ (Formica and Regelson, 1995), which could be much higher if dietary supplements are also consumed. The objective of the current study was, therefore, to determine the antibacterial, antibiofilm hemolytic activities and phytochemical study of aerial parts of Moringa oleifera.

\section{Material and Methods}

\subsection{Identification and collection of the plant material}

Aerial parts of Moringa oleifera were collected from different regions of Pakistan and the herbarium specimens were subjected to analysis in Quaid e Azam University, Islamabad Pakistan. Plant samples were identified by (Plant taxonomist) Department of Plant Sciences, Quaid-e-Azam university, Islamabad (Voucher Specimen No. ISL 1367).

\subsection{Preparation of plant extracts}

The freshly collected different aerial parts of Moringa olifera were washed with distilled water and dried at 40 ${ }^{\circ} \mathrm{C}$. The dried samples were extracted with methanol. The extracts were filtered through Whatman filter paper I and then concentrated on rotary evaporator model (Eyela Tokyo Rikakikakki Co Ltd Japan) at $45{ }^{\circ} \mathrm{C}$. Dried samples were kept at $4^{\circ} \mathrm{C}$ till used for the assay. The extracts were solubilised and diluted with sterile water to get the desired concentration.

\subsection{Bacterial culture and inoculums preparation}

The identity and purity of the bacterial strains Bacillus subtilis JS-2004 and Escherichia coli (E. coli) ATCC 25922 used for the test were verified by the institute of Microbiology University of agriculture, Faisalabad, Pakistan. Bacterial strains were cultured overnight at $37^{\circ} \mathrm{C}$ in Nutrient agar (Oxoid, UK).

\subsection{Antibacterial activity}

The extracts obtained were screened for their antibacterial activity in comparison with standard antibiotic (Ciprofloxacin $30 \mu \mathrm{g} / \mathrm{dish}$ ) (Oxoid, UK) in-vitro by disc diffusion method using B. subtilis and E. coli as a test organisms. The filter discs (6 $\mathrm{mm}$ in diameter) were individually impregnated with each extract, placed on the agar plates which had previously been inoculated with the tested microorganisms. The diameter of the growth inhibition zones (zone reader) was measured in millimeters for the organisms and was compared to the control (Bashir et al., 2015).

\subsection{Anti-biofilm activity of the aerial parts}

The effect of the methanolic extracts of the aerial parts of Moringa oleifera on biofilm formation was examined following the method of (Yarwood et al., 2004) micro titer plate assay with a little modification. The appropriate concentration of plant extracts was added to the wells of 96 microtiter plates having bacterial cultures inoculated in LB (Luria-Bertani) broth. Negative and positive controls were also included in the experiment.Plates were incubated for $24 \mathrm{~h}$ at $37^{\circ} \mathrm{C}$. After incubation the growth medium was discarded, and the wells were washed thrice with sterile physiological saline $(0.85 \% \mathrm{NaCl})$. The adhered cells were stained with $0.1 \%$ crystal violet for $10 \mathrm{~min}$. The excessive stain was removed by washing twice with $0.85 \% \mathrm{NaCl}$, while cellbound dye was eluted with $33 \%$ glacial acetic acid and the absorbance of eluted solution was measured at 578 $\mathrm{nm}$ using a micro titer plate reader. After incubation, the plant extracts were carefully removed and reduction in biofilm formation was determine by measuring the absorbance of biofilms at $570 \mathrm{~nm}$ using a micro titer plate reader. 


\subsection{Hemolytic Activity}

Hemolytic activity of the samples was studied by the method used by (Rubab et al., 2015) Three millimeter human red blood cells were collected from Department of Clinical Medicine and Surgery, University of Agriculture, Faisalabad, Pakistan. Blood centrifuged for $5 \mathrm{~min}$ at $1000 \times \mathrm{g}$ plasma was discarded and cells were washed with thrice with $5 \mathrm{~mL}$ of chilled $\left(4^{\circ} \mathrm{C}\right)$ sterile isotonic Phosphate-buffered saline (PBS) $\mathrm{pH}$ 7.4. Erythrocytes $10^{8}$ cells per $\mathrm{m}$ were preserved for each assay. The concentration of each extract $(100 \mu \mathrm{g} / \mathrm{mL})$ was mixed with human $\left(10^{8}\right.$ cells $\left./ \mathrm{mL}\right)$ separately. The samples were incubated for $35 \mathrm{~min}$ at $37^{\circ} \mathrm{C}$ and agitated after $10 \mathrm{~min}$. Immediately after incubation the samples were placed on ice for 5 min then centrifuged for $5 \mathrm{~min}$ at $1000 \mathrm{x}$. Supernatant were taken from each tube and diluted 10 time with chilled $\left(4^{\circ} \mathrm{C}\right)$ PBS. Triton X-100 (0.1\% v/v) was taken as positive control and phosphate buffer saline (PBS) was taken as negative control and pass through the same process. The absorbance was noted at $576 \mathrm{~nm}$ using $\mu$ Quant (Bioteck, USA). The \% RBCs lysis for each sample was calculated as;

\section{Percentage hemolysis $=($ Absorbance of sample-Absorbance of blank $\div$ Absorbance of positive control}

\subsection{Quantitavive Analysis of phytochemicals}

\subsubsection{Quantitative determination of flavonoids}

Standard solutions of rutin $(1000 \mathrm{mg} / \mathrm{l})$ were prepared by diluting $10 \mathrm{mg}$ of rutin in $5 \mathrm{ml}$ methanol to a $10 \mathrm{ml}$ volumetric flask and make up to the mark. Standard solutions of concentration $(10,20,30,40$ and $50 \mathrm{mg}$ /1) were diluted from above to stock solution and used for routine calibration curve. $0.5 \mathrm{ml}$ of methanol extract solution was mixed with $2.5 \mathrm{ml}$ of methanol, $0.5 \mathrm{ml}$ of $2 \%$ aluminum chloride, allowed to stand at room temperature for 60 minutes. The absorbance of the reaction mixture was measured with UV-Visible spectrophotometer at the maximum absorption length $420 \mathrm{mn}$. The result is expressed in $\mathrm{mg} / \mathrm{g}$.

\subsubsection{Determination of total phenols}

This method was established to determine total phenols, known as the colorimetric method, in which the phenolic compounds react with the folin ciocalteu reagent (tungstophosphate and molybdophosphate). At basic $\mathrm{pH}$, resulting in a blue coloration capable of spectrophotometric determination at $700 \mathrm{~nm}$. A $10 \%$ solution of gelatin was then used to ensure the sequestration of the tannins, the percentage of tannins whose absorbance was referred to gallic acid and read at $700 \mathrm{~nm}$ was obtained from both determination. The standard solution of Gallic acid was prepared by taking $50 \mathrm{mg}$ of gallic acid and dissolved it in 1 liter of water. A series of standard solutions was prepared with concentration of $0.10,20,30,40$ and $50 \mathrm{mg} / 1$.

\subsubsection{Determination of alkaloids}

The method designated by sharma (2008) was followed. 1 gram of sample was extracted with $20 \mathrm{ml}$ ethanol in $20 \% \mathrm{H} 2 \mathrm{SO} 4$ (1:1) for $5 \mathrm{mins}$ and filtered. Five militers of $60 \% \mathrm{H} 2 \mathrm{SO} 4$ was added to $1 \mathrm{ml}$ of the filtrate. Five milliliter of $0.5 \%$ formaldehyde in $60 \% \mathrm{H} 2 \mathrm{SO} 4$ was added. After mixing and allowing to stand for $3 \mathrm{hrs}$, the absorbance of the complex in chloroform was measured at $565 \mathrm{~nm}$ against target prepared by Spectrophotometer (shimadzu uv mini-1240). Atropine was used as standard.

\subsection{Statistical analysis}

The results are presented as mean \pm S.E.M. Data were determined using student's t-test. $\mathrm{P}$ values $<0.01$ and 0.05 were taken as significant.

\section{Results and Discussion}

In regards to antibacterial activity the zones of inhibition for different extracts are shown in (Table 1). The result showed that the methanolic extracts of various aerial parts of $M$. oleifera showed variable antibacterial activity against selected bacterial pathogens equivalent to that of standard against the entire tested organism. Methanolic extracts of leaf showed maximum B. subtilis $(21 \mathrm{~mm})$, E. coli $(19 \mathrm{~mm})$. In a similar way the results of methanolic bark extract showed maximum B. subtilis $(19 \mathrm{~mm})$, E. coli $(18 \mathrm{~mm})$. Flower extract showed maximum B. subtilis $(15 \mathrm{~mm})$, E. coli $(14 \mathrm{~mm})$. The Fruit showed maximum B. subtilis $(14 \mathrm{~mm})$, E. coli $(12$ $\mathrm{mm})$. Stem showed minimum B. subtilis $(12 \mathrm{~mm})$, E. coli $(11 \mathrm{~mm})$. Leaf extract of Moringa oleifera showed high zone of inhibition against $B$. subtilis $(21 \mathrm{~mm})$ and $(19 \mathrm{~mm})$ against $E$. coli equivalent to that of the standard. All the organisms tested were affected by the extract with appropriate zones of inhibition. The diameter of zone of inhibition was greater in case of leaf and bark extract as compared to other extracts of M. oleifera as shown in Table 1. 
Table 1. Antibacterial activity of different extracts of M.O against Bacillus subtilis and E. coli.

\begin{tabular}{lllc}
\hline \multirow{2}{*}{ Sample / Control } & \multirow{2}{*}{ Amount $\boldsymbol{\mu g} / \mathbf{d i s c}$} & \multicolumn{2}{c}{ Zone of inhibition $(\mathbf{m m})$} \\
\cline { 3 - 4 } & & $21 \pm 0.10$ & $\boldsymbol{E}$. coli \\
$\mathrm{mLe}$ & 100 & $19 \pm 0.11$ & $19 \pm 0.05$ \\
$\mathrm{mBa}$ & 100 & $15 \pm 0.12$ & $18 \pm 0.09$ \\
$\mathrm{mFl}$ & 100 & $14 \pm 0.15$ & $14 \pm 0.04$ \\
$\mathrm{mFr}$ & 100 & $12 \pm 0.19$ & $12 \pm 0.06$ \\
$\mathrm{mSt}$ & 100 & $23 \pm 0.02$ & $11 \pm 0.09$ \\
Ciprofloxacin & 30 & \multicolumn{2}{c}{$22 \pm 0.01$} \\
\hline
\end{tabular}

Values are presented as mean \pm S.E. of triplicate experiments.

mLe: methanolic extract of leaf $\mathrm{mBa}$ : methanolic extract of Bark; mFl: methanolic extract of Flower; mfr: methanolic extract of fruit; mSt: methanolic extract of Stemciprofloxacin (control)

Table 2. Biofilm inhibition against Bacillus subtilis.

\begin{tabular}{lll}
\hline Sample / Control & Absorbance (nm) & \% Inhibition \\
\hline $\mathrm{mLe}$ & 0.376 & 63.17 \\
$\mathrm{mBa}$ & 0.428 & 58.08 \\
$\mathrm{mFl}$ & 0.110 & 52.63 \\
$\mathrm{mFr}$ & 0.727 & 28.79 \\
$\mathrm{mSt}$ & 0.753 & 26.24 \\
Ciprofloxacin & 0.195 & 80.90 \\
\hline
\end{tabular}

Values are presented as mean \pm S.E. of triplicate experiments.

mLe: methanolic extract of leaf, mBa: methanolic extract of Bark, mFl: methanolic extract of Flower, mfr: methanolic extract of fruit, mSt: methanolic extract of Stem

Table 3. Biofilm inhibition against E. coli.

\begin{tabular}{lll}
\hline Sample / Control & Absorbance (nm) & \% Inhibition \\
\hline $\mathrm{mLe}$ & 0.33 & 66.32 \\
$\mathrm{mBa}$ & 0.35 & 64.28 \\
$\mathrm{mFl}$ & 0.48 & 51.01 \\
$\mathrm{mFr}$ & 0.66 & 32.65 \\
$\mathrm{mSt}$ & 0.65 & 27.69 \\
Ciprofloxacin & 0.131 & 86.63 \\
\hline
\end{tabular}

Values are presented as mean \pm S.E. of triplicate experiments.

mLe: methanolic extract of leaf, mBa: methanolic extract of Bark, mFl: methanolic extract of Flower, mfr: methanolic extract of fruit, mSt: methanolic extract of Stem

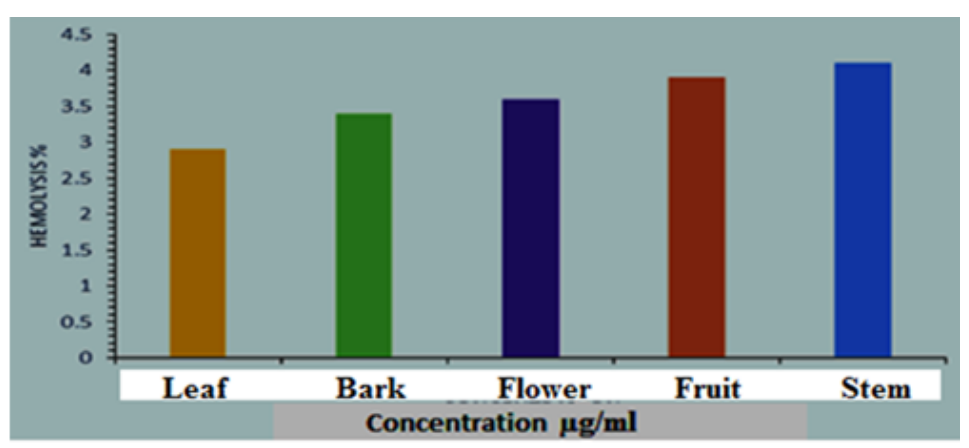

Figure 1. Hemolysis of various aerial parts of Moringa oleifera. 


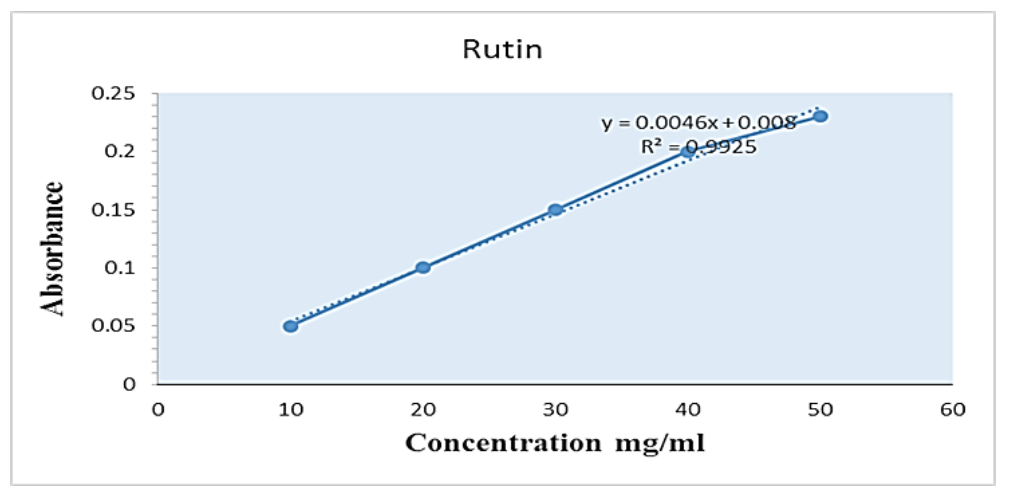

Figure 2. Calibration curve for the quantification of flavonoids.

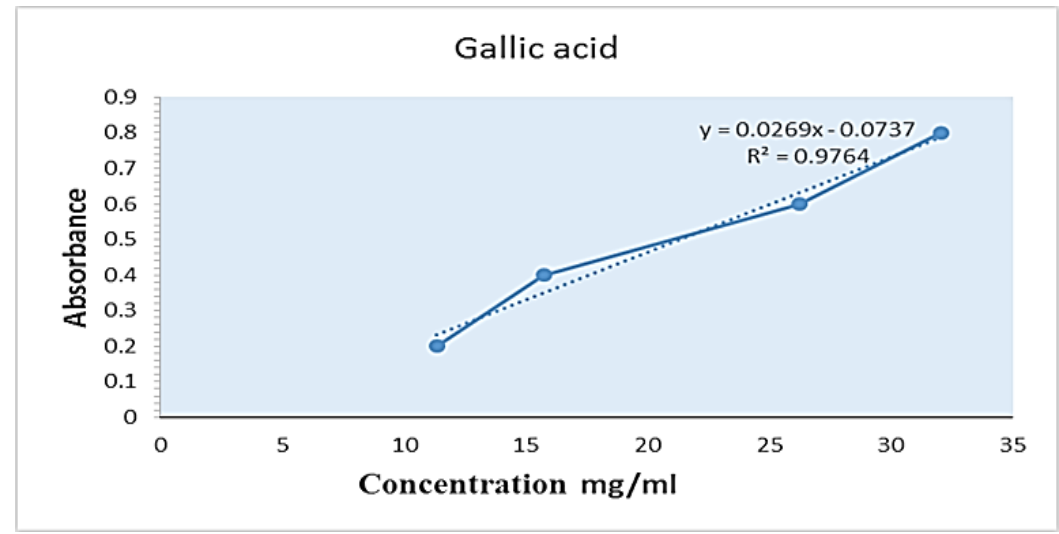

Figure 3. Calibration curve for the quantification of phenols and tannins.

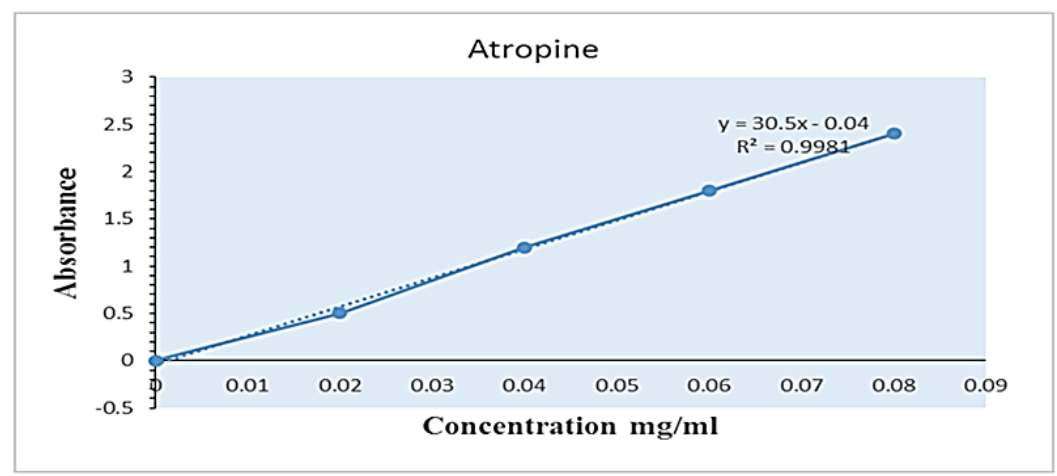

Figure 4. Calibration curve for the quantification of alkaloids.

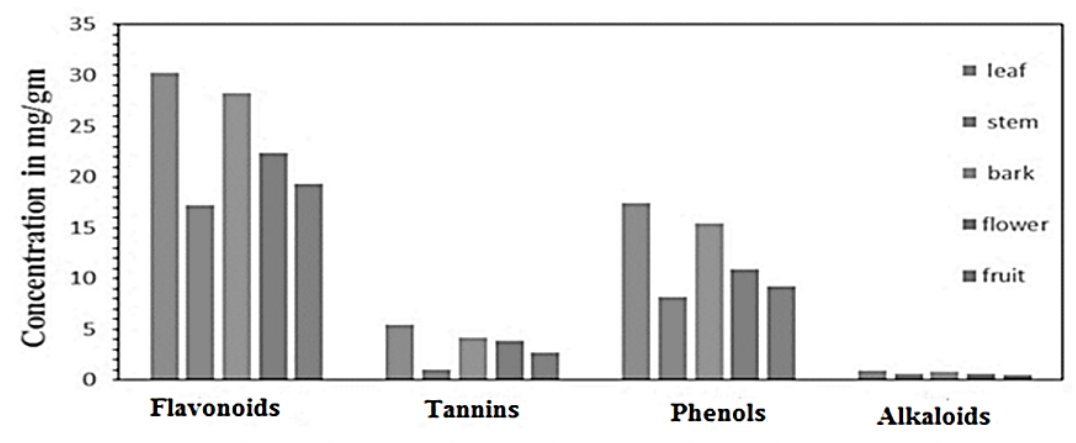

Figure 5. Quantitative analysis of phytochemicals. 
Antibiofilm potential of five plant extracts of Moringa oleifera was also evaluated in this study. Extracts of leaf, bark and seed exhibited most powerful biofilm inhibition against $E$. coli and B. subtilis as compared to other aerial parts of the same plant shown in Table 2 and Table 3 . The hemolytic activity of the methanolic extracts of different aerial parts of MO were screened against human blood erythrocytes. Methanolic extracts of leaf, bark, flower, fruit and stem showed low hemolytic activity (at dose $100 \mu \mathrm{g} / \mathrm{ml}$ ) toward human erythrocytes as shown in Figure 1. The calibration curve used to quantify the flavonoids present in the moringa is shown in Figure 2. This curve shows a good linearity at concentrations of 10 to $50 \mathrm{mg} / 1$. With this curve we proceeded to quantify the flavonoids present in this plant, the concentration of this metabolite varied significantly in relation to different aerial parts of Moringa oleifera. Figure 3 Shows the calibration curve that was made for quantification of phenols and tannins, an excellent linearity is observed at concentrations between 10-50 mg / 1 of gallic acid. Figure 4 Shows the calibration curve to quantify the alkaloids in Moringa oleifera, in which good linearity is observed at concentrations of 0.2 to $1.2 \mathrm{mg} / \mathrm{ml}$ Atropine. From this curve we proceeded to quantify the alkaloids in this plant, the development of this metabolite varied little in relation to their different aerial parts. The variability of the concentration of flavonoids, alkaloids, tannins and phenols in different aerial parts of the plant is shown in Figure 5 which is very significant. The total flavonoid contents were calculated from the extracts of leaf, stem, bark, flower and fruit using the standard curve of rutin solution, respectively (Figure 5). The data were interpreted regarding RAE (rutin equivalents) of the extract, respectively. The extract of leaf showed a significantly high flavonoid content $(30.26 \pm 0.73 \mathrm{mg} \mathrm{QAE} / \mathrm{g})$ than the bark whereas the extracts of bark showed flavonoid contents $(28.26 \pm 0.73 \mathrm{mg}$ QAE$/ \mathrm{g})$ higher than that of flower $(22.42 \pm 0.98 \mathrm{mg}$ QAE$/ \mathrm{g})$, fruit (19.36 $\pm 0.18 \mathrm{mg}$ QAE/g) and stem $(17.24 \pm 0.08 \mathrm{mg}$ QAE/g). The total flavonoid contents of the different extracts are in the range of leaf extract>bark extract>flower extract>fruit extract $>$ stem extract as shown in (Figure 5). The tannins contents were studied in extracts utilizing the Folin-Ciocalteu's reagent and is expressed in terms of gallic acid equivalent (the standard curve equation: $\mathrm{y}=0.0269 \mathrm{x}-0.0737, \mathrm{R} 2=0.9764$ ). The values obtained for the concentration of tannin contents are expressed as $\mathrm{mg}$ of GA/g of extract. The results of phenolic content of the aerial parts showed a significant difference $(\mathrm{p}<0.05)$. The highest concentration of tannins $(5.43 \pm 0.10 \mathrm{mg}$ of $\mathrm{GA} / \mathrm{g}$ ) was examined in methanolic extract of leaf then the bark whereas the extracts of bark showed tannins contents $(4.22 \pm 0.10 \mathrm{mg}$ of GA/g) higher than that of flower $(3.85 \pm 0.25 \mathrm{mg}$ of $\mathrm{GA} / \mathrm{g})$, fruit $(2.70 \pm 0.10 \mathrm{mg}$ of $\mathrm{GA} / \mathrm{g})$ and stem $(0.99 \pm 0.01 \mathrm{mg}$ of $\mathrm{GA} / \mathrm{g})$. The total phenolic contents (TPC) were calculated from the methanolic extracts of leaf, stem, bark, flower and fruit using the standard curve of Gallic acid solution, respectively (Figure 5). The data were interpreted regarding GAE (gallic acid equivalents). The results of phenolic content of the aerial parts showed a significant difference $(p<0.05)$. The extracts of the leaf showed the highest level of phenolic content of $17.4 \pm 0.20(\mathrm{mg} \mathrm{GAE} / \mathrm{g})$ which was significantly higher than that of the phenolic content of the bark $15.38 \pm 0.08$ (mg GAE/g) whereas the extracts of bark showed phenolic contents $28.26 \pm 0.73$ (mg GAE/g) higher than that of flower $10.88 \pm 0.15$ (mg GAE/g), fruit $9.27 \pm 0.0$ ( $\mathrm{mg}$

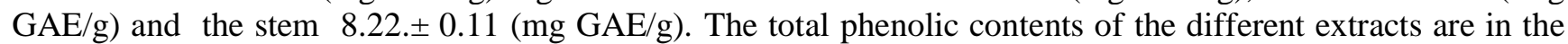
range of leaf extract $>$ bark extract $>$ flower extract $>$ fruit extract $>$ stem extract as shown in (Figure 5).

The alkaloid contents were examined in leaf, stem, bark, flower and fruit extracts and expressed in terms of atropine equivalent as $\mathrm{mg}$ of $\mathrm{AE} / \mathrm{g}$ of extract (the standard curve equation: $\mathrm{y}=30.5 \mathrm{x}-0.04, \mathrm{R} 2=0.9981$ ). The highest concentration of alkaloid $(0.88 \pm 0.02 \mathrm{mg}$ of $\mathrm{AE} / \mathrm{g})$ was found in leaf extract follow by the bark $(0.80 \pm$ $0.73 \mathrm{mg}$ of $\mathrm{AE} / \mathrm{g})$, flower $(0.60 \pm 0.0 \mathrm{mg}$ of $\mathrm{AE} / \mathrm{g})$ and fruit $(0.56 . \pm 0.01 \mathrm{mg}$ of $\mathrm{AE} / \mathrm{g})$ while least concentration of alkaloids $(0.54 . \pm 0.0 \mathrm{mg}$ of $\mathrm{AE} / \mathrm{g})$ was found in the stem extract respectively.

Bacteriological studies in this present work reveal that the antimicrobial activity of the aerial parts of $M$. oleifera affected predominantly bacterial species. The antimicrobial activity of extract might be due to the presence of lipophilic compounds that might bind inner to the cytoplasmic membrane (Jabeen et al., 2008). Several authors have reported antimicrobial activities of plant extracts on food borne pathogens (Moreira et al., 2005; Kotzekidou et al., 2007; Afolabi, 2007; Atiqur Rahman and Sun, 2009). Owing to the significant use of antibiotics, a variety of micro-organism strains with multi-drug resistance have developed (Khan et al., 2009). Millions of people die every year due to infectious diseases (Dubey et al., 2012). Medicinal plants are precious natural reservoir as they are assumed to have supernatural effects on the mankind and being used by almost all nations of the world. Most of the people in developing an developed countries use traditional medicines originated from medicinal plant (Igbinosa et al., 2009). Various parts of Moringa oleiferaahave been recognized as being good sources of phenolic acids glucosinolates and flavonoids (Amaglo et al., 2010; Coppin et al., 2013), carotenoids tocopherols (Saini et al., 2014).

In the present investigation, the antimicrobial and antibiofilm activity of the extracts of aerial parts of Moringa oleifera was assayed against two pathogenic microorganisms Bacillus subtilis and $E$. coli at 
same concentrations the extracts of Moringa oleifera showed a broad-spectrum antibacterial and antibiofilm activity.

The findings of the present study showed potential antibacterial and antibiofilm activity against Bacillus subtilis and Escherichia coli. The antimicrobial and antibiofilm activity of various aerial parts of Moringa oleifera was in order: $\mathrm{mLe}>\mathrm{mBa}>\mathrm{mFl}>\mathrm{mFr}>\mathrm{mSt}$ and these activities were due to the presence of phytochemical compounds like saponins, terpenoids, alkaloids, carbohydrates, fats, tannins, flavonoids and sterols. The various phytochemicals and secondary metabolites have been reported to exhibited antimicrobial activities (Trentin $e t$ al., 2013; Manner et al 2013). The leaf and bark showed highest zone of inhibition at the concentration of 100 $\mu \mathrm{g} / \mathrm{disc}$ and as an antibiofilm against bacterial pathogens while at same concentration of $100 \mu \mathrm{g} / \mathrm{dics}$ the other extracts showed least antibacterial and antibiofilm activity against the studied bacteria.

\section{Conclusions}

All aerial parts of Moringa oleifera showed varying antibacterial, antibiofilm activities. The result also revealed that the methanolic extracts of aerial parts of $M$. oleifera possess very low hemolytic activity and these results may contribute to the growing information about different aerial parts of $M$. oleifera which can be used to discover an antibacterial agent for developing new pharmaceuticals. Their intake could be useful in the prevention of diseases. The extracts of different aerial parts of $M$. oleifera can provide a low-cost and maintainable method toward disease reduction and can ultimately restore the quality of life of the rural and rurban people in developing countries like Pakistan.

\section{Acknowledgments}

We honestly acknowledge the contribution of doctor Naseem Rauf, Chemical Meteorology Division, National Physical Standard laboratory (PCSIR), Plot No. 16, Sector H-9 Islamabad, Pakistan for their support in this research.

\section{Conflict of interest}

None to declare.

\section{References}

Afolabi FE, 2007. Chemical composition and antibacterial activity of Gongrenema latifolium. Journal of Zhejiang University Science, 8: 352-358.

Amaglo NK, RN Bennett and RB Lo Curto, 2010. Profiling selected phytochemicals and nutrients in different tissues of the multipurpose tree Moringa oleifera L., grown in Ghana. J. Food Chemistry, 122:1047-1054.

Anwar F, S Latif, M Ashraf and AH Gilan, 2007. Moringa oleifera: a food plant with multiple medicianl uses. J. Phytotherapy Research, 21:17-25.

Arora DS, GJ Kaur and H Kaur, 2009. Antibacterial activity of tea and coffee their extracts and preparations. Int. J. Food Properties, 12: 286-294.

Atiqur R and CK Sun, 2009. In vitro control of food borne and food spoilage bacteria by essential oiland ethanol extracts of Lonicera japonica Thunb. Food Chemistry, 16: 670- 675.

Bashir MS, S Ali, S Shahzadi and M Shahid, 2015. Synthesis, characterization and biological activities of Organotin (IV) Complexes with l-Lysine Monohydrate. Russian Journal of General Chemistry, 85:15321537.

Chuang P, C Lee, J Chou, M Murugan, B Shieh and H Chen, 2007. Antifungal activity of crude and essential oil of Moringa oleifera Lam. Bioresource Technology, 98: 232-236.

Cook NC and S Samman, 1996. Flavonoids- chemistry, metabolism, cardioprotective effects, and dietary sources. Nutritional Biochemistry, 7: 66-76.

Coppin JP, Xu and YHChen, 2013. Determination of flavonoids by LC/MS and anti-inflammatory activity in Moringa oleifera. J. Functional Foods, 5:1892-1899.

Domingo D and M López-Brea, 2003. Plants with antimicrobial action. Spanish Magazine of Chemotherapy, 16: 385-393.

Doughari JH, MS Pukuma and N De, 2007. Antibacterial effects of Balanites aegyptiaca and Moringa oleifera Lam. on Salmonella typhi. Afr. J. Biotechnol., 6: 2212- 2215.

Dubey D, S Rath, MC Sahu, NK Debata and RN Padhy, 2012. Antimicrobials of plant origin against TB and other infections and economics of plant drugs-introspection. Indian Journal of Traditional Knowledge,11: 225-233. 
Dubey NK, R Kumar, and P Tripathi, 2004.Global promotion of herbal medicine: India's opportunity. Current Science. 86: 37-41.

Fahey JW, 2005. Moringa oleifera: a review of the medical evidence for its nutritional, therapeutic, and prophylactic properties: Part 1," Trees Life J., 1: 5-19.

Formica JV and W Regelson, 1995. Review of the biology of quercetin and related bioflavonoids. Food Chem. Toxicol., 33: 1061-1080.

Frankel EN, AL Waterhouse and PL Teissedre, 1995. Principal phytochemicals in selected California wines and their antioxidant activity in inhibiting oxidation of human lowdensity lipoproteins. J. Agric. Food Chem., 43: 890- 894.

Gustavo HFV, JA Mourao, AM Angelo, RA Costa and RHS dos Fernandes Vieira, 2010. Antibacterial effect (in vitro) of Moringa oleifera and Annona muricata against Gram positive and Gram negative bacteria. Journal of the Rev. Inst. Med. Trop. Sao Paulo, 52:129-132.

Igbinosa OO, EO Igbinosa and OA Aiyegoro, 2009. Antimicrobial activity and phytochemical screening of stem bark extracts from Jatropha curcas (Linn). African. J. Pharmacy and Pharmacology, 3: 58-62.

Jabeen R, M Shahid, A Jamil and M Ashraf, 2008. Microscopic evaluation of the antimicrobial activity of seed extracts of Moringa oleifera. Pakistan Journal of Botany, 40:1349-58.

Jamil A, M Shahid, MM Khan and M Ashraf, 2007. Screening of some medicinal plants for isolation of antifungal proteins and peptides. Pakistan Journal of Botany, 39: 211-221.

Kekuda N, MTR Prashith, D Swathi, KV Nayana, BA Meera and TR Rohini, 2010. Antibacterial and antifungal efficacy of steam distillate of M. oleifera Lam. J. Pharmaceutical Sciences and Research, 2: 34-37.

Khan R, B Islam, M Akram, S Shakil, A Ahmad, S Ali, SM Siddiqui and AU Khan, 2009. Antimicrobial activity of five herbal extracts against multi drug resistant (MDR) strains of bacteria and fungus of clinical origin. Molecules, 14: 586-597.

Kotzekidou P, P Giannakidis and A Boulamatsis, 2008. Antimicrobial activity of some plant extracts and essential oils against food borne pathogens in vitro and on the fate of inoculated pathogens in chocolate. LWT - Food Science and Technology, 41:119-127.

Lockett CT, CC Calvet and LE Grivetti, 2000. Energy and micronutrient composition of dietary and medicinal wild plants consumed during drought. Study of rural Fulani, northeastern Nigeria. Int. J. Food Science and Nutrition, 51:195-208.

Mahajan SG and AA Mehta, 2010. Immunosuppressive activity of ethanolic extract of seeds of Moringa oleifera Lam. in experimental immune inflammation. J. Ethnopharmacol., 130: 183-186.

Manner S, M Skogman, D Goeres, P Vuorela and A Fallarero, 2013. Systematic exploration of natural and synthetic flavonoids for the inhibition of Staphylococcus aureus biofilms. Int. J. Mol. Sci., 14: 19434-19451.

Moreira MR, AG Ponce, CE del Valle and SI Roura, 2005. Inhibitory parameters of essential oils to reduce a food-borne pathogen. LWT - Food Science and Technology, 38: 565- 570.

Nikkon F, A Saud, MH Rahman and ME Haque, 2003. In vitro antimicrobial activity of the compound isolated from chloroform extract of Moringa oleifera. Pak. J. Biol. Sci., 6: 1888-1890.

Qaiser M, 1973. Moringaceae. In: Nasir, E., Ali, S.I. (Eds.), Flora of West Pakistan, Department of Botany, University of Karachi, Karachi, Pakistan 1973; pp. 1-4.

Rojas JJ, VJ Ochoa, SA Ocampo and JF Munoz, 2006. Screening for antimicrobial activity of ten medicinal plants used in Colombian folkloric medicine: A possible alternative in the treatment of non- nosocomial infections. BMC Complementary Alternative Medicines, 6: 2.

Rubab K, MA Abbasi, Aziz-ur-Rehman, SZ Siddiqui, M Ashraf, A Shaukat, I Ahmad, MA Lodhi, FA Khan, M Shahid and MN Akhtar, 2015. Convergent synthesis of new $N$-substituted 2-\{[5-(1H-indol-3-ylmethyl)1,3,4-oxadiazol-2-yl]sulfanyl $\}$ acetamides as suitable therapeutic agents. Brazilian Journal of

Pharmaceutical Sciences, 51: 931-94.

Saini R, NP Shetty, M Prakash and P Giridha, 2014. Effect of dehydration methods on retention of carotenoids, tocopherols, ascorbic acid and antioxidant activity in Moringa oleifera leaves and preparation of a RTE product. J Food Science Technology, 51: 2176-2182.

Shamsa F, H Monsef, R Ghamooshi and M Verdian-rizi, 2008. Spectrophotometric determination of total alkaloids in some Iranian medicinal plants. Thai J. Pharm. Sci., 32:17-20.

Sreelatha S and Padma, 2009. Antioxidant activity and total phenolic content of moringa oleifera leaves in two stages of maturity. Plant Foods for Human Nutrition, 64: 303-311.

Sudha P, SM Asdaq, SS Dhamingi and GK Chandrakala, 2010. Immunomodulatory activity of methanolic leaf extract of Moringa oleifera in animals. Indian J. Physiology Pharmacology, 54: 133- 140. 
Trentin DS, DB Silva, MW Amaral, KR Zimmer, MV Silva and NP Lopes, 2013.Tannins possessing bacteriostatic effect impair Pseudomonas aeruginosa adhesion and biofilm formation. PLoS One, 8: e66257.

Yarwood JM, DJ Bartels, EM Volper and EP Greenberg. Quorum sens-ing in Staphylococcus aureus biofilms. Journal of Bacteriology, 186:1838-1850. 